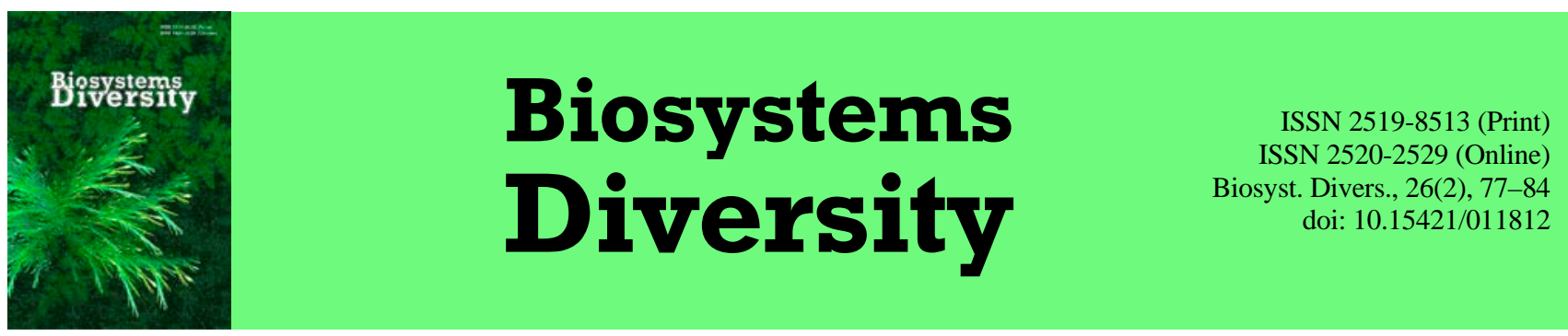

\title{
Comparative analysis of the leaf anatomy of Echinacea purpurea and E. pallida
}

\author{
T. N. Belaeva, A. N. Butenkova \\ Siberian Botanical Garden of Tomsk State University, Tomsk, Russia
}

Article info

Received 06.04.2018

Received in revised form 11.05.2018

Accepted 14.05.2018

Siberian Botanical Garden of Tomsk State University, Lenina Ave., 36,

Tomsk, 634050, Russia.

Tel.: +7-3822-52-98-33.

E-mail: tbel10@yandex.ru Belaeva, T. N., \& Butenkova, A. N. (2018). Comparative analysis of the leaf anatomy of Echinacea purpurea and
E. pallida. Biosystems Diversity, 26(2), 77-84. doi:10.15421/011812

This article contains a comparative analysis of the anatomical structure of the rosette and stem leaves of Echinacea purpurea and E. pallida. The plants were grown on the experimental site of the Siberian Botanical Garden, located in the southeastern part of Tomsk (Western Siberia). Temporary preparations of the leaves were prepared by cutting them on a freezing microtome MZ-2. Photographs of leaf microscopy and microscopic measurements were made on a light microscope. Anomocyte type of stomatal complex is characteristic for the studied species. Leaves of the studied species are amphistomatic, rosette leaves of E. purpurea are hypostomatic. The stomatal index of E. purpurea was 1.5 (stem leaves, upper epidermis) and 24.4-25.5 (lower epidermis). In the leaf blade of E. purpurea, the signs are revealed as mesomorphic (the presence of relatively large dorsoventral leaves, moderate development of integumentary, conducting and mechanical tissues) and a xeromorphic-heliomorphic structure. A complex of xeromorphic-heliophytic features of the E. pallida leaf has been identified, which increase its drought resistance; the mean values of the stomatal index of the upper and lower epidermis were 24.8-28.7. There are 10 characteristics that have significant differences in mean values when comparing leaves of E. purpurea and E. pallida: the size of the stomata of the lower epidermis, the thickness of the mesophyll of the leaf, its layers and the leaf laminae free of the vascular bundle, the area of the vascular bundle and their constituents.

Keywords: epidermis; stomatal complex; phloem; xylem; ecological anatomy

\section{Сравнительный анализ анатомии листовых пластинок Echinacea purpurea и E. pallida}

\section{Т. Н. Беляева, А. Н. Бутенкова}

Сибирский ботанический сад Томского государственного университета, Томск, Россия

\begin{abstract}
Приводятся результаты анализа анатомической структуры розеточных и стеблевых листьев Echinacea purpurea и E. pallida. Растения выращивали на экспериментальном участке Сибирского ботанического сада, расположенном в юго-восточной части Томска (Западная Сибирь). Временные препараты листьев подготавливали путем их нарезания на замораживающем микротоме МЗ-2. Фотографии микропрепаратов листьев и микроскопические измерения сделаны на световом микроскопе. Для исследованных видов характерен аномоцитный тип устьичного аппарата. Тип листа амфистоматический, розеточные листья эхинацеи пурпурной гипостоматические. Устьичный индекс E. purpurea составил 1,5 (стеблевые листья, верхняя эпидерма) и 24,4-25,5 (нижняя эпидерма). В листовой пластинке E. purpurea выявлены признаки как мезоморфной (наличие относительно крупных дорзовентральных листьев; умеренное развитие покровной, проводящей и механической тканей), так и ксероморфно-гелиоморфной структуры. Выявлен комплекс ксероморфногелиофитных признаков листа E. pallida, повышающих ее засухоустойчивость; средние значения устьичного индекса верхней и нижней эпидермы составили 24,8-28,7. Установлено 10 характеристик, имеющих достоверные отличия средних значений при сравнении листьев E. purpurea и E. pallida: размеры устьиц нижней эпидермы, толщина мезофилла листа, его слоев и пластинки листа, свободной от проводящих пучков, площадь проводящих пучков и их составляющих.
\end{abstract}

Ключевые слова: эпидерма; устьичный аппарат; флоэма; ксилема; экологическая анатомия

\section{Введение}

Одной из приоритетных задач отечественного здравоохранения является расширение ассортимента лекарственных средств за счет внедрения в медицинскую практику препаратов растительного происхождения. Для комплексного лечения и профилактики иммунодефицитных состояний в настоящее время широко используются виды рода Echinacea Moench. Род Echinacea (Asteraсеае) включает 9 видов (Kindscher, 2016; Urbatsch et al., 2006). Ecтественный ареал рода охватывает восточные и центральные об- ласти Северной Америки (Urbatsch et al., 2006).

Виды рода Echinacea широко культивируются в качестве ценных лекарственных, орнаментальных и медоносных растений. E. purpurea (L.) Moench, E. pallida (Nutt.) Nutt., E. angustifolia D. C. используются для получения различных препаратов и биологически активных добавок противовоспалительного, противовирусного и иммуностимулирующего действия, а также повышения неспецифической устойчивости организма к неблагоприятным воздействиям окружающей среды (Dorn et al., 1997; Hu \& Kitts, 2000; Speroni et al., 2002; Sloley, 2001; Birt et al., 2008). Растения со- 
держат комплекс биологически активных веществ: водорастворимые полисахариды, эфирные масла, лактоны, алкиламиды, лектины, флавоноиды, производные оксикоричных кислот, дубильные вещества, сапонины, кумарины, витамин С и др. (Leung \& Foster, 1996; Pietta et al., 1998; Bauer, 1999; Perry et al., 2001; Barnes et al., 2005; El-Gengaihi, 2008). E. purpurea является фармакопейным растением в России: качество ее травы регламентируется фармакопейной статьей ФС 2.5.0055.15.

Видам рода Echinacea посвящены многочисленные публикации, однако информация об анатомии листовых пластинок ограничена. Анатомические исследования листьев проводили Н. W. Keller (1962), A. C. Keller (2012), Getko et al. (2000), Samorodov \& Pospelov (2001), Kurkin et al. (2009), Dyakonova et al. (2011), Kmitiené \& Ragažinskienè (2008), Atkočiūnaitė (2007) и другие, преимущественно с целью отбора признаков для диагностики сырья. Сведения об анатомии листовой пластинки, главным образом эхинацеи пурпурной, приводятся в различных Фармакопеях (Upton et al., 2011).

Согласно данным, полученным Samorodov \& Pospelov (2001), устьичный аппарат эпидермы листьев трех видов эхинацеи (E. purpurea, E. pallida, E. angustifolia) аномоцитного типа. Исследованные виды отличались по размерам и числу клеток трихом. Наиболее опушенной у всех трех видов являлась верхняя эпидерма, а количество трихом на нижней эпидерме уменьшалось на 39,4-63,3\%.

Getko et al. (2000) провели многофакторный анализ морфологических, анатомических и некоторых химических признаков 6 форм E. purpurea. Они обнаружили, что толщина губчатой паренхимы базального листа находится в обратной зависимости от высоты и диаметра стеблей, а количество язычковых цветков в соцветии коррелирует со степенью развития нижней эпидермы листа, то есть с развитием покровных тканей. Содержание цикориевой кислоты оказалось напрямую связанным с размерами клеток хлорофиллоносной паренхимы (ширина и площадь палисадной паренхимы, длина и площадь клеток губчатой паренхимы), что можно, по мнению авторов, использовать в качестве теста на содержание действующего вещества в культивируемых растениях.

Kurkin et al. (2009) методами цифровой микроскопии установлено, что для диагностики растительного сырья эхинацеи пурпурной могут быть использованы следующие признаки строения листа: клетки эпидермы с извилистыми стенками, аномоцитный тип устьиц, простые волоски, заполненные бурым содержимым и расположенные по жилкам.

Анатомия листа эхинацеи бледной менее изучена. Согласно Keller (1962), наиболее отличительной особенностью листовой пластинки данного вида является сильно выраженная изолатеральная тенденция. Однако Dyakonova et al. (2011) описывают лист E. pallida как дорзовентральный. Нет единства и в определении типа устьичного аппарата эхинацеи бледной: одни авторы (Samorodov \& Pospelov, 2001; Dyakonova et al., 2011) описывают его как аномоцитный, а другие (Atkočiūnaitè, 2007) относят к анизоцитному типу с устьичным индексом 12,2 (нижняя эпидерма) 21,9 (верхняя эпидерма).

Изучение экологии видов, включая проведение анатомических исследований, лежит в основе их акклиматизации и интродукции, а также является теоретической основой повышения их продуктивности и оптимизации факторов среды. Растение, попадая в новые для него природно-климатические условия, испытывает комплекс разнообразных воздействий. Результатом обмена информации между организмом и средой являются приспособительные реакции, позволяющие ему адаптироваться к стрессовым факторам. Листья как органы транспирации и фотосинтетической активности обладают значительной пластичностью: их строение в значительной степени зависит от условий водоснабжения и освещенности, при которых происходит формирование растений. В то же время именно водный стресс является одной из основных причин гибели растений в процессе онтогенетического развития. В связи с этим, исследование анатомического строения листьев весьма информативно для понимания проблемы устойчивости интродуцентов к экстремальным условиям среды, в том числе водному стрессу, и позволяет выявить их адаптационный потенциал. Изучение внутривидовой изменчивости растений, культивируемых в новых природно-климатических условиях, является важным направлением биоэкологических исследований (Nekhajchenko et al., 2014).

Цель настоящего исследования - сравнительная анатомическая оценка листовых пластинок двух наиболее ценных в лекарственном отношении видов рода: E. purpurea и E. pallida. Полученные результаты позволят определить значимость изученных признаков для выявления структурной адаптации видов в условиях подтайги Западной Сибири.

\section{Материал и методы исследований}

Исследования проводили в 2016-2017 гг. в Сибирском ботаническом саду (Томск, Россия) в лесной природно-климатической зоне, подзоне южной тайги. Климат Томска резкоконтинентальный, характеризуется продолжительной суровой зимой, весенними возвратами холодов, ранними осенними заморозками и жарким, хотя и коротким, летом.

Средняя годовая температура воздуха составляет $-0,6^{\circ} \mathrm{C}$; максимальная температура приходится на июль, минимальная - на январь. Средняя продолжительность безморозного периода 114 суток. По количеству осадков (в среднем 517 мм в год) Томск и его окрестности относятся к зоне умеренного увлажнения. За три летних месяца выпадает 40\% годовой суммы, зимой около $15 \%$, весной и осенью, соответственно - $18 \%$ и $27 \%$. Годовой максимум осадков приходится на июль. Относительная влажность воздуха изменяется в пределах 60-82\%, максимум относительной влажности отмечается в мае (Kashinskij, 1982).

Растения выращивали на экспериментальном участке Сибирского ботанического сада, расположенном в юго-восточной части Томска, из семянок местной репродукции. Участок открытый, хорошо освещенный. Почвы серые лесные, среднего механического состава, окультуренные. Материалами для исследования послужили розеточные и стеблевые листья E. purpurea и E. pallida, собранные в период массового цветения. Для исследования использовали сформированные листовые пластинки, стеблевые листья отбирали из средней части побега.

Временные препараты листьев подготавливали путем их нарезания на замораживающем микротоме М3-2. Толщину среза устанавливали на 60-90 мкм. Изучение анатомического строения проводили с использованием светового микроскопа на поперечных срезах листьев. Поперечные срезы делали в средней части листа, в пятикратной повторности на листьях, собранных с пяти побегов; для каждого образца анализировали не менее 25 срезов листьев. Число клеток и устьиц на 1 мм² эпидермы подсчитывали после отделения кожицы в средней части листа. В качестве методической основы для изучения анатомического строения листовых пластинок растений использованы общепринятые методики, изложенные в статье Belaeva et al. (2014). Устьичный индекс рассчитывали по формуле Kästner (1972). Фотографии микропрепаратов листьев и микроскопические измерения сделаны на световом микроскопе Carl Zeiss Axio Lab. A1 с цифровой камерой AxioCam ERc 5s при помощи программы Axio Vision 4.8.

Результаты измерений обрабатывали с использованием программы Statistica 8.0 (StatSoft Inc., USA). Определяли следующие показатели: $\mathrm{x}$ - среднюю арифметическую; SE - стандартную ошибку средней арифметической, CV - коэффициент вариации, Min-Max - минимальное и максимальное значение. При оценке достоверности различий независимых выборок оценивали: t-value значение статистики t-критерия, рассчитанное в предположении равных дисперсий в выборках; $\mathrm{P}$ - уровень значимости для t-критерия (односторонний критерий), F-ratio var. - F-отношение дисперсий (значение статистики F-критерия Фишера) и P var. - ypoвень значимости для F-критерия. Уровни варьирования приняты по Г. Н. Зайцеву: CV > 20\% - высокий, CV = 11-20\% - средний, $\mathrm{CV}<10 \%$ - низкий. Анатомические показатели эпидермы считаются маловариабельными, если коэффициент вариации CV < 
$20 \%$, средневариабельными - при CV = 20-40\%, сильновариабельными - при CV > 40\% (Belaeva et al., 2014).

Пределы варьирования размеров листовых пластинок приведены для культивируемых образцов местной репродукции.

\section{Результаты}

Феноритмотип исследованных видов эхинацеи в условиях Томска длительновегетирующий, весенне-летне-осеннезеленый с периодом зимнего покоя.

Виды Echinacea относятся к полурозеточным многолетним поликарпическим растениям: имеют розеточные и стеблевые листья, которые характеризуются определенным структурным градиентом в пределах растения, то есть отличаются как своим расположением, так и периодичностью развития. Отрастание розеточных листьев у образцов эхинацеи в 2016-2017 гг. происходило в конце апреля - первой декаде мая. Исследованные виды зацветали в июле: сначала эхинацея бледная (в первой и во второй декадах), а затем пурпурная (во второй и третьей декадах). Семена созревали во второй половине сентября - октябре. Таким образом, в начале вегетации фотосинтетический потенциал эхинацеи пурпурной формируется за счет розеточных листьев, а в период цветения - в значительной степени за счет стеблевых листьев.

E. purpurea (рис. 1) имеет розеточные листья на черешках до 26 см длиной, от яйцевидной, продолговато-яйцевидной, эллиптической до ланцетной формы, зубчатые, редко цельнокрайние, шершавые, обычно с сердцевидным основанием и удлиненной верхушкой. Листовые пластинки до 28 см длиной и 4,0-14,2 см шириной. Стеблевые листья в количестве 5-15 на побеге, очередные, ланцетные или продолговато-яйцевидные, с черешком, самые верхние почти сидячие, до 20 см длиной, 1,5-10 (11) см шириной.

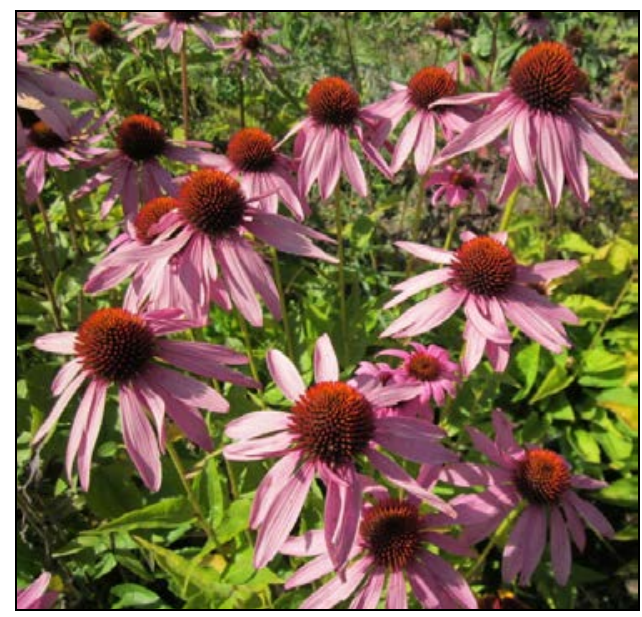

Рис. 1. E. purpurea на экспериментальном участке Сибирского ботанического сада

Верхняя эпидерма однослойная, покрыта кутикулой, состоит из клеток полигональной (многоугольной) формы, с менее извилистыми антиклинальными стенками по сравнению с нижней

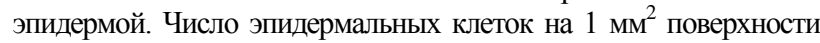
листа составляет в среднем 516-604 (табл.; рис. 2).

Тип устьиц аномоцитный, они овальные, окружены (2) 3-5 (6) околоустьичными клетками. Замыкающие клетки устьиц в среднем 32,3-36,8 мкм длиной с амплитудой изменчивости от 22,1 до 41,6 мкм и в среднем 28,0-30,1 мкм шириной с пределами варьирования от 25,4 до 33,9 мкм.

В верхней эпидерме розеточных листьев исследованного образца устьица отсутствовали, то есть они являлись гипостоматическими (подобный тип листьев характерен для большинства мезофитных растений). Листовые пластинки стеблевых листьев амфистоматические, причем на нижней эпидерме устьиц в 5,5 раза больше, чем на верхней (табл.). Расположение устьиц преимущественно на нижней стороне листа объясняется тем, что потеря воды при транспирации происходит здесь медленнее, чем на верхней эпидерме. Соот- ветственно, устьичный индекс E. purpurea составил 1,5 (стеблевые листья, верхняя эпидерма) и 24,4-25,5 (нижняя эпидерма).

\section{Таблица}

Количественные и морфометрические признаки строения листовой пластинки E. purpurea и E. pallida

\begin{tabular}{|c|c|c|c|c|}
\hline \multirow{3}{*}{ Признаки } & \multicolumn{4}{|c|}{$\begin{array}{l}\mathrm{x} \pm \mathrm{SE} \\
\mathrm{CV}, \%\end{array}$} \\
\hline & \multicolumn{2}{|c|}{ E. purpurea } & \multicolumn{2}{|c|}{ E. pallida } \\
\hline & $\begin{array}{c}\text { розеточный } \\
\text { лист }\end{array}$ & $\begin{array}{c}\text { стеблевой } \\
\text { лист }\end{array}$ & $\begin{array}{c}\text { розеточный } \\
\text { лист }\end{array}$ & $\begin{array}{c}\text { стеблевой } \\
\text { лист }\end{array}$ \\
\hline Число клеток верхней & $515,8 \pm 9,6$ & $604,2 \pm 10,9$ & $263,7 \pm 4,7$ & $251,5 \pm 6,6$ \\
\hline эпидермы на 1 мм², шт. & 9,3 & 9,0 & 9,0 & 13,1 \\
\hline Число клеток нижней & $577,9 \pm 10,5$ & $574,7 \pm 10,0$ & $284,8 \pm 7,7$ & $238,1 \pm 6,2$ \\
\hline эпидермы на 1 мм², шт. & 9,1 & 8,7 & 13,5 & 12,9 \\
\hline Число устьиц верхней & & $9,6 \pm 3,7$ & $87,0 \pm 3,8$ & $92,2 \pm 4,0$ \\
\hline эпидермы на 1 мм², шт. & - & 192,5 & 21,9 & 21,4 \\
\hline Число устьиц нижней & $186,9 \pm 5,8$ & $197,8 \pm 7,0$ & $114,6 \pm 4,6$ & $81,3 \pm 3,9$ \\
\hline эпидермы на 1 мм², шт. & 15,6 & 17,8 & 20,0 & 24,1 \\
\hline Длина устьиц на верх- & & $35,8 \pm 0,7$ & $47,5 \pm 0,6$ & $53,0 \pm 0,5$ \\
\hline ней эпидерме, мкм & & 9,8 & 6,1 & 4,4 \\
\hline Ширина уст & & $28,3 \pm 0,4$ & $38,0 \pm 0,3$ & $39,9 \pm 0,7$ \\
\hline хней эпидерме, мкм & - & 6,0 & 4,0 & 8,2 \\
\hline Длина устьиц на ниж- & $32,3 \pm 0,7$ & $36,8 \pm 0,6$ & $47,5 \pm 0,6$ & $54,4=$ \\
\hline ней эпиде & 10,3 & 8,8 & 6,7 & 4,8 \\
\hline Ширинаустьц наниж- & $30,1 \pm 0,4$ & $28,0 \pm 0,3$ & $37,5 \pm 0,6$ & $41,7 \pm 0,8$ \\
\hline ней эпидерме, мкм & 7,2 & 4,8 & 7,7 & 9,5 \\
\hline УИ верхней & & $1,5 \pm 0,6$ & $24,8 \pm 1,0$ & $26,9 \pm 1,1$ \\
\hline эпидермы, \% & - & 186,2 & 20,0 & 19,7 \\
\hline УИ г & $24,4 \pm 0,6$ & $25,5 \pm 0,8$ & $28,7 \pm 0,9$ & $25,4 \pm$ \\
\hline эпидермы, \% & 12,1 & 14,9 & 15,8 & 20 \\
\hline Толщина листа по цен- & $1271,6 \pm 7,4$ & $1257,5 \pm 7,9$ & $946,2 \pm 3,2$ & $1337,5 \pm 7,3$ \\
\hline тральной жилке, мкм & 2,9 & 3,2 & 1,7 & 2,7 \\
\hline Толщина I & $241,1 \pm 2,6$ & $374,8 \pm 8,4$ & $471,5 \pm 7,2$ & $652,4 \pm 11,5$ \\
\hline & 5,5 & 11,2 & 7,7 & \\
\hline Толщина мезофилла & $182,9 \pm 1,7$ & $311,5 \pm 10,3$ & $431,6 \pm 7,5$ & $571,1=$ \\
\hline листа, мкм & 4,7 & 16,5 & 8,7 & 9 \\
\hline Толщина палисадной & $79,3 \pm 1,6$ & $138,9 \pm 6,7$ & $186,2 \pm 2,0$ & 272,1 \\
\hline ткани, мкм & 10,2 & 24,0 & 5,5 & 7, \\
\hline Толщина губчатой & $86,1 \pm 1,7$ & $183,1 \pm 5,6$ & $214,8 \pm 3,8$ & $291,0 \pm 10,1$ \\
\hline ткани, мкм & 9,9 & 15,2 & 8,8 & 17,3 \\
\hline $\begin{array}{l}\text { Отношение толщины } \\
\text { палисадной/губчатой } \\
\text { ткани }\end{array}$ & $\begin{array}{c}0,9 \pm 0,0 \\
14,9\end{array}$ & $\begin{array}{c}0,8 \pm 0,0 \\
20,1\end{array}$ & $\begin{array}{c}0,9 \pm 0,0 \\
9,4\end{array}$ & $\begin{array}{c}0,9 \pm 0,0 \\
16,9\end{array}$ \\
\hline Толщина верхней & $24,7 \pm 0,6$ & $36,3 \pm 0,8$ & $34,3 \pm 1,2$ & $32,7=$ \\
\hline эпидермю & & 10,6 & & \\
\hline Толщина нижней & $29,3 \pm 0,9$ & $31,3 \pm 0,8$ & $35,0 \pm 0,8$ & $36,5 \pm$ \\
\hline эпидермы, мкм & 15,7 & 12,4 & 10,9 & 15 \\
\hline $\begin{array}{l}\text { Высота клеток верх- } \\
\text { него слоя мезофилла, } \\
\text { мкм }\end{array}$ & $\begin{array}{c}58,4 \pm 1,2 \\
9,9\end{array}$ & $\begin{array}{c}93,2 \pm 5,1 \\
27,4\end{array}$ & $\begin{array}{c}106,8 \pm 1,9 \\
8,7\end{array}$ & $\begin{array}{c}155,3 \pm 3,7 \\
12,0\end{array}$ \\
\hline $\begin{array}{l}\text { Ширина клеток верх- } \\
\text { него слоя мезофилла, } \\
\text { мкм }\end{array}$ & $\begin{array}{c}26,1 \pm 0,9 \\
16,7\end{array}$ & $\begin{array}{c}32,0 \pm 1,4 \\
21,2\end{array}$ & $\begin{array}{c}32,3 \pm 1,0 \\
15,3\end{array}$ & $\begin{array}{c}36,4 \pm 1,1 \\
14,7\end{array}$ \\
\hline Плотность опушения & $2,6 \pm 1,2$ & $1,9 \pm 1,4$ & $1,9 \pm 1,1$ & $2,6 \pm 1,2$ \\
\hline $\begin{array}{l}\text { на верней стороне на } \\
1 \text { мм², шт. }^{2}\end{array}$ & 233,9 & 366,4 & 276,4 & 233,9 \\
\hline Плотность опушения & & $2,6 \pm 1,2$ & $1,9 \pm 1,1$ & $1,3 \pm 0,9$ \\
\hline 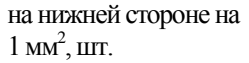 & - & $\begin{array}{l}2,0 \pm 1,2 \\
233,9\end{array}$ & $\begin{array}{l}1,0 \pm 1,1 \\
276,4\end{array}$ & $\begin{array}{l}1,0 \pm 0,3 \\
346,1\end{array}$ \\
\hline Площадь поперечно- & $102141,7 \pm$ & $94321,0 \pm$ & $52323,7 \pm$ & $120410,6 \pm$ \\
\hline го сечения ксилемы, & 1838,4 & 984,1 & 687,6 & 1654,8 \\
\hline $\mathrm{MKM}^{2}$ & 8,4 & 5,2 & 6,6 & 6,9 \\
\hline Площадь & $119832,8 \pm$ & $83620,1 \pm$ & $33425,3 \pm$ & $77132,5 \pm$ \\
\hline & 1930,9 & 1739,2 & 1046,9 & 2405,4 \\
\hline флоэмы, мкм² & 7,6 & 10,4 & 15,7 & 15,6 \\
\hline Площадь поперечно- & $226701,0 \pm$ & $179917,6 \pm$ & $84579,4 \pm$ & $195747,2 \pm$ \\
\hline го сечения проводя- & 3209,7 & 2835,7 & 1327,3 & 3520,2 \\
\hline щего пучка, мкм² & 6,6 & 7,9 & 7,9 & \\
\hline Отношение площа- & $0,9 \pm 0,0$ & $1,1 \pm 0,0$ & $1,6 \pm 0,1$ & $1,6 \pm 0,1$ \\
\hline дей ксилемы/флоэмы & 10,2 & 10,2 & 15,6 & 17,9 \\
\hline
\end{tabular}

Лист эхинацеи пурпурной дорзовентральный: мезофилл гетерогенный, дифференцирован на столбчатую (1-2 слоя) и губчатую паренхиму. Толщина палисадной и губчатой тканей составляет в среднем у розеточных листьев соответственно 79,3 мкм и 86,1 мкм, у стеблевых листьев - 138,9 и 183,1 мкм. Губчатый ме- 
зофилл хорошо развит, расположен абаксиально и состоит из рыхловатых клеток неправильной формы с межклетниками. Толщина

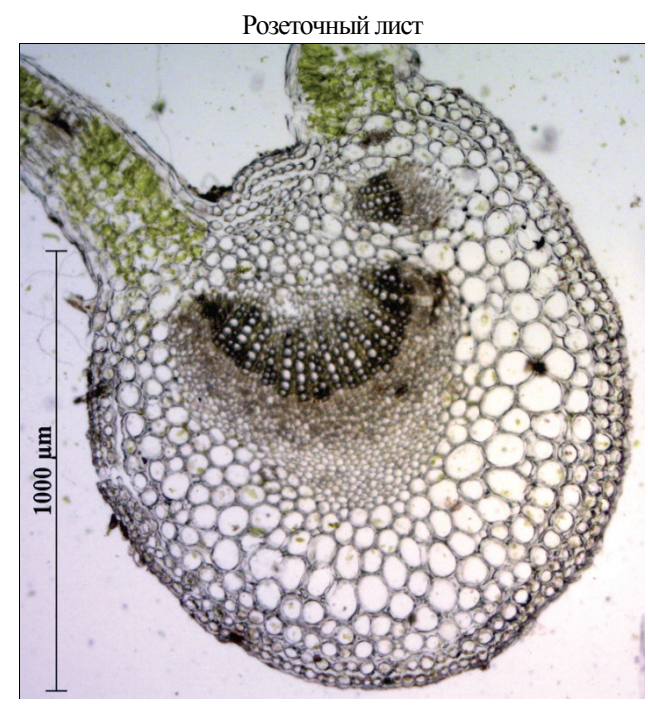

палисадной паренхимы незначительно, в 0,8-0,9 раза, меньше толщины губчатой ткани (табл.; рис. 2).
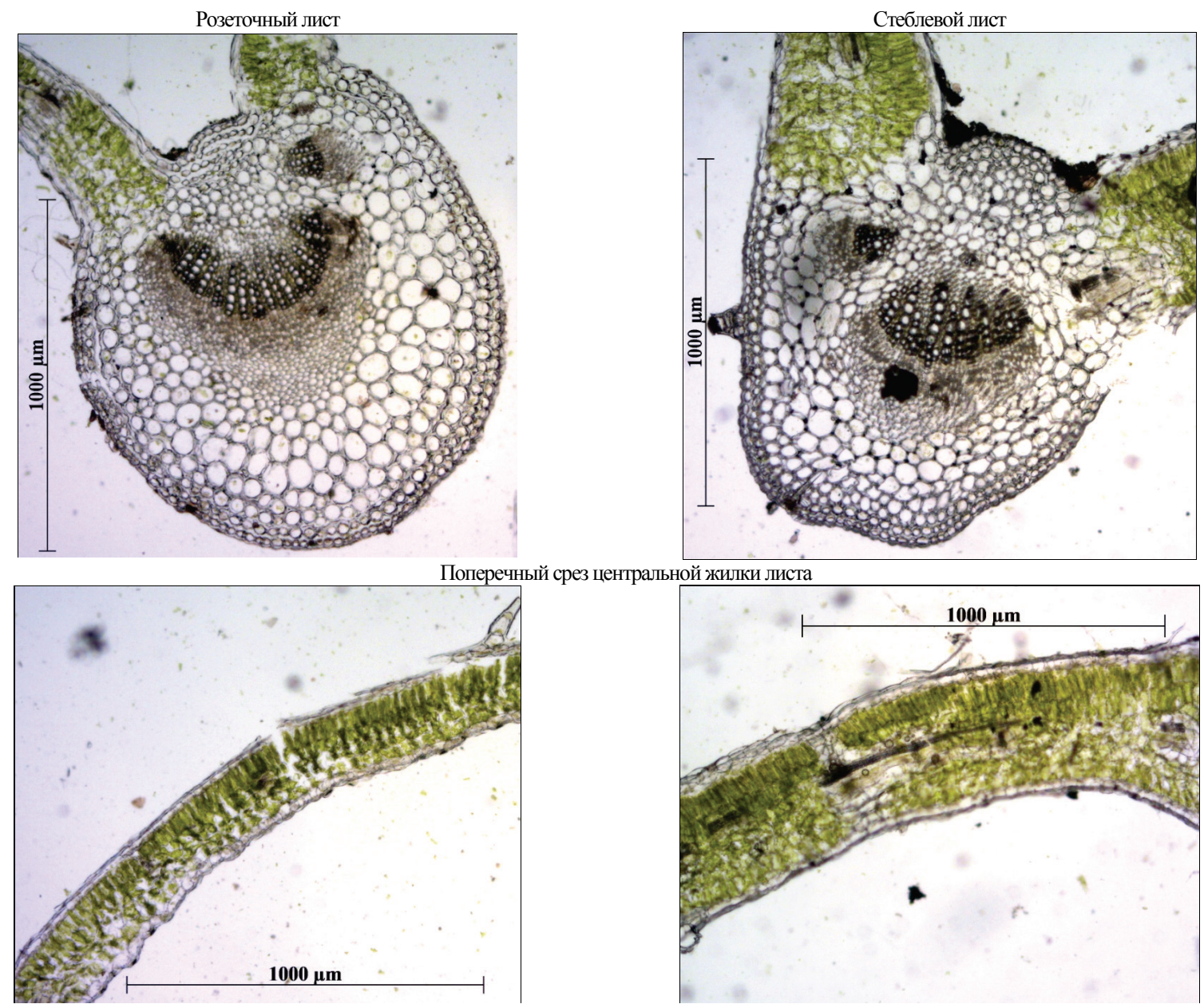

перечный срез центральной жилки листа
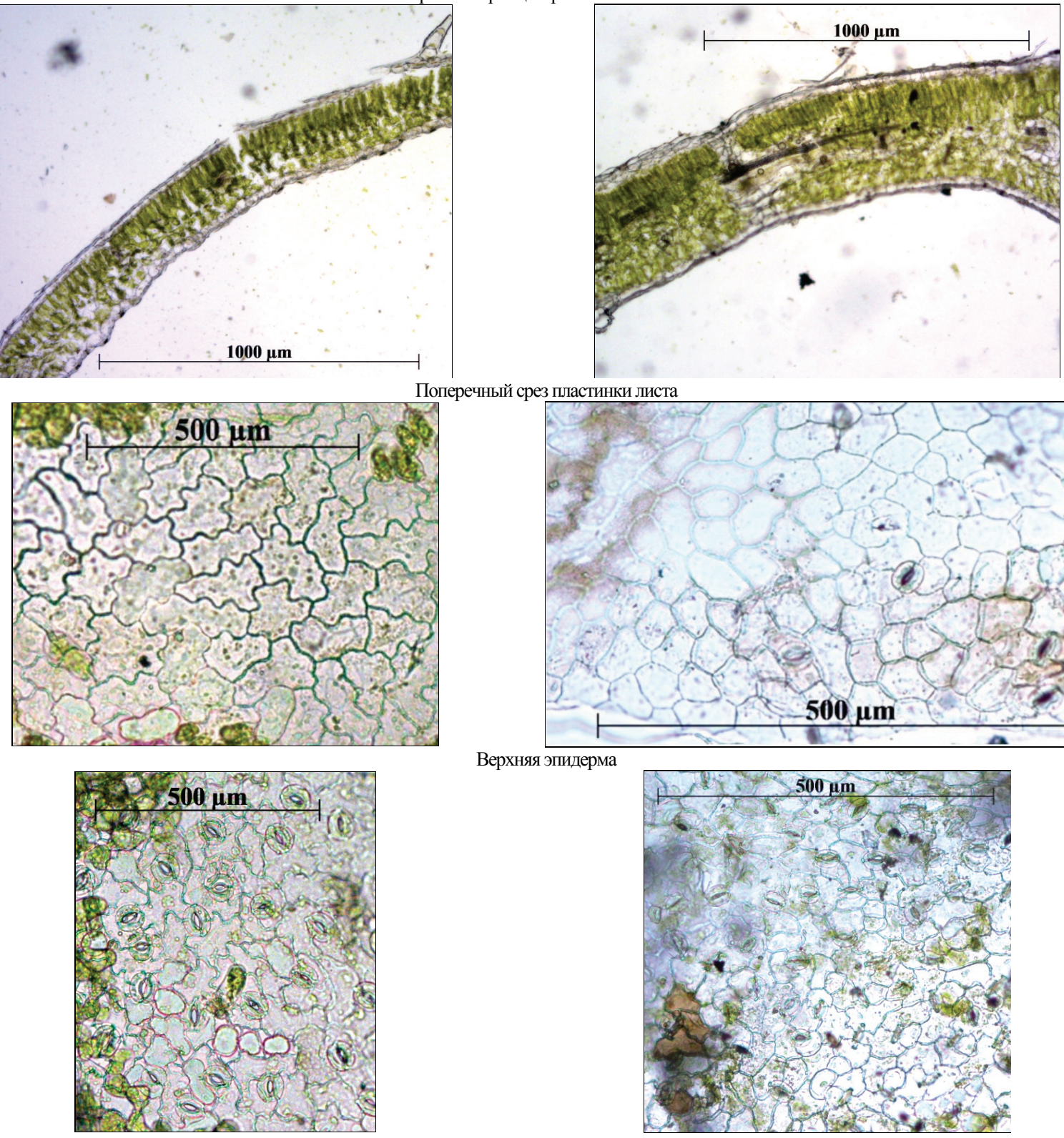

оперечный срез пластинки листа

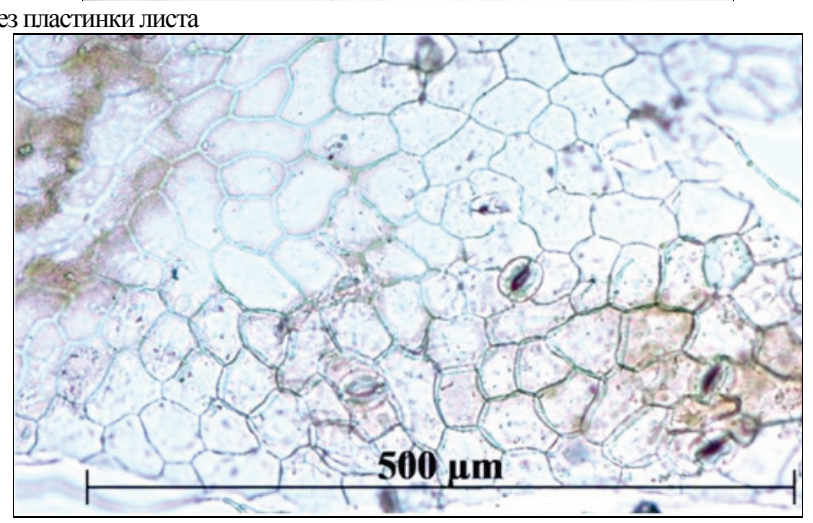

Верхняя эпидерма

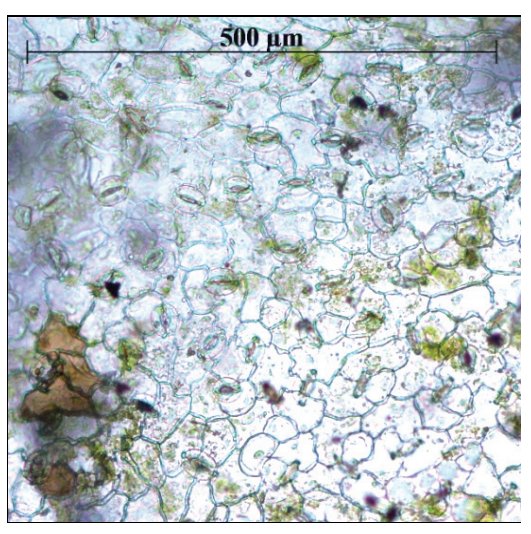

Нижняя эпидерма

Рис. 2. Поперечные срезы листьев и эпидерма розеточного и стеблевого листьев E. purpurea 

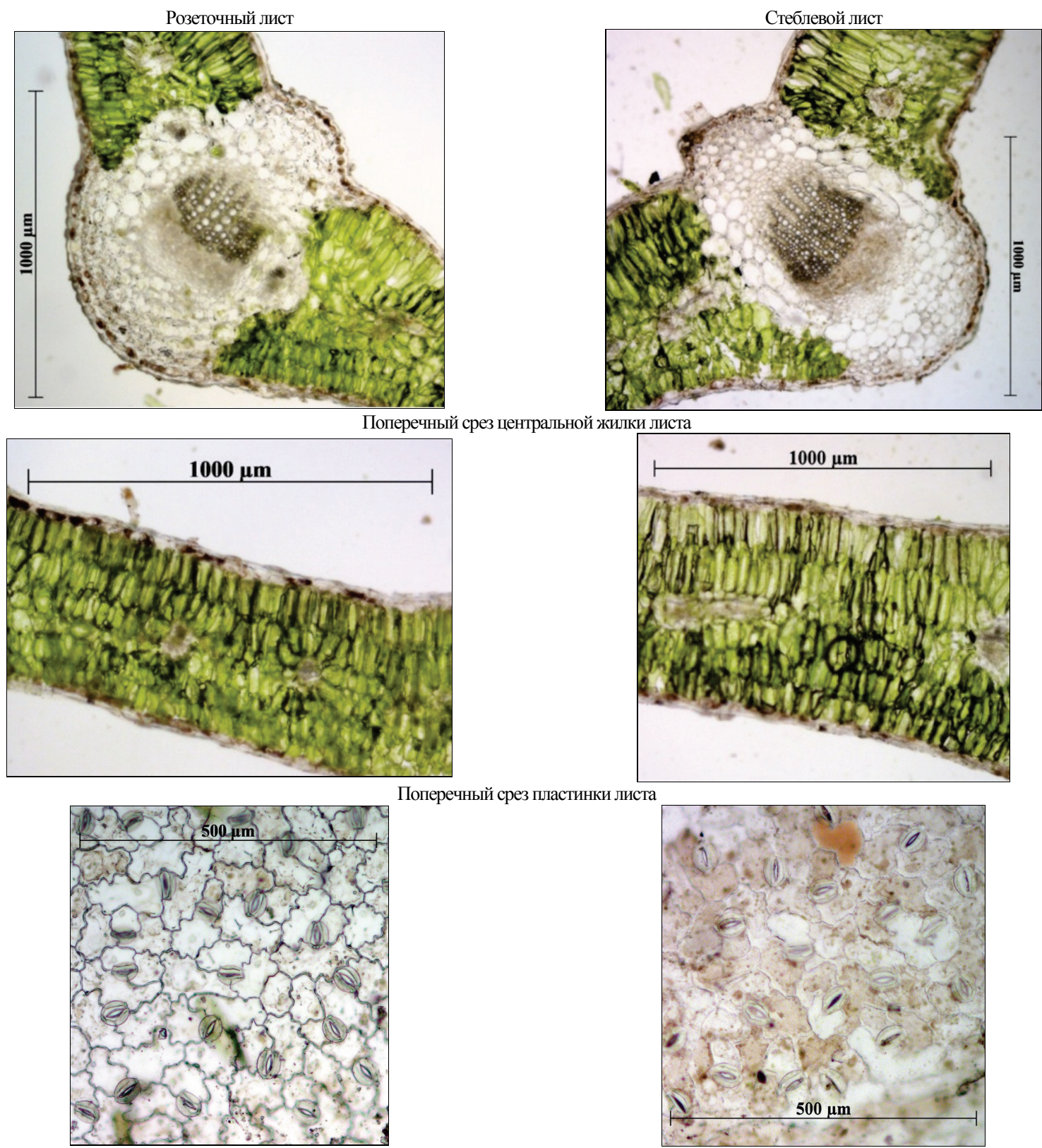

Поперечный срез пластинки листа

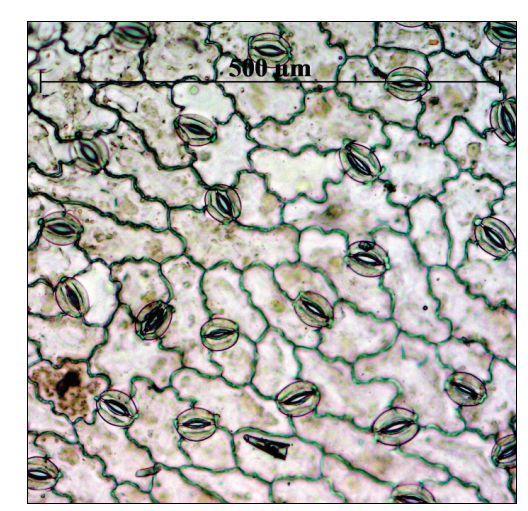

Верхняя эпидерма
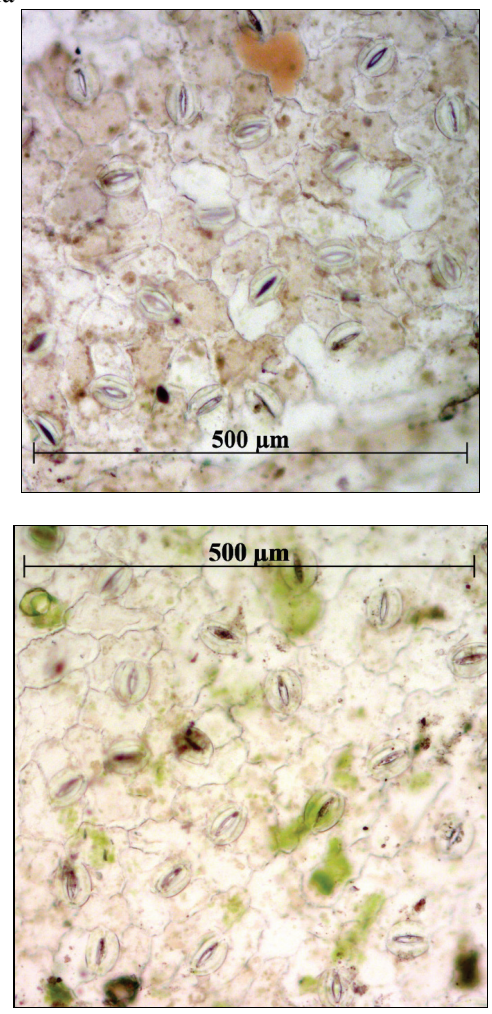

Нижняя эпидерма

Pис. 3. Поперечные срезы листьев и эпидерма розеточного и стеблевого листьев E. pallida

Толщина пластинки розеточных листьев в средней части составляет в среднем 241,1 мкм, у стеблевых листьев - 374,8 мкм.

Сосудисто-волокнистые пучки пронизывают мезофилл листа. Коллатеральные пучки закрытые. Выше и ниже сосудисто-волокнистых пучков находится колленхима, примыкающая к эпидерме. Отношение площадей поперечного сечения ксилемы и флоэмы составило 0,9 у розеточных и 1,1 у стеблевых листьев, то есть ксилема и флоэма развиты у эхинацеи пурпурной примерно в равной степени. Защитная функция эпидермы усиливается в результате развития на ней трихом. Трихомы разной длины в основном простые или изредка вдоль жилок - железистые. Клетки у основания волосков образуют розетку, что отмечено в литературе (Kurkin et al., 2009). Трихомы обычны на верхней эпидерме розеточных листьев, на нижней эпидерме - единичные или отсутствуют. 
E. pallida (Nutt.) Nutt. Листья простые, цельные, цельнокрайние, ланцетные, опушенные с обеих сторон, до 4,3 см шириной. Розеточные листья вместе с черешком до 25 (35) см длиной, с клиновидным основанием; стеблевые листья до 19 см длиной, верхние сидячие. Результаты исследования эпидермальных структур у эхинацеи бледной показали следующее. Пластинки розеточных и стеблевых листьев амфистоматные. Верхняя эпидерма однослойная, с заметной кутикулой. Клетки верхней и нижней эпидермы неправильной формы с извилистыми стенками. Эпидермальные клетки в среднем 32,7-36,5 мкм толщиной с амплитудой изменчивости от 21,0 до 48,3 мкм. Среднее число клеток на 1 мм² $^{2}$ 238,1-284,8 (табл.; рис. 3). Kmitienė \& Ragažinskienė (2008), описывая анатомию листа эхинацеи бледной в Литве, приводят более высокие средние значения высоты эпидермальных клеток в пределах от 46,3 до 56,3 мкм.

Устьица овальные, крупные, окружены 3-4 клетками, аномоцитного типа. Размеры устьиц в среднем 47,5-54,4 мкм длиной, с амплитудой изменчивости в пределах 42,1-60,9 мкм и в среднем 37,5-41,7 мкм шириной с амплитудой изменчивости от 29,5 до 47,3 мкм (рис. 3). На нижней стороне пластинки розеточных листьев устьиц несколько больше (в среднем 114,6 против 87,0 на верхней стороне), однако отличия не являются статистически достоверными при $\mathrm{P}<0,05$. Стеблевые листья также достоверно не отличаются по числу устьиц на нижней (от 64 до 128, в среднем 81,3 ) и верхней (от 48 до 128, в среднем 92,2) эпидерме. Устьичный индекс верхней и нижней эпидермы розеточных и стеблевых листьев составляет в среднем 24,8-28,7 при амплитуде изменчивости от 14,3 до 37,5 (табл.).

На листьях отмечены трихомы двух типов: в основном - простые многоклеточные (до 5-6 клеток) с удлиненной апикальной клеткой (рис. 2), а также железистые.

Пластинка листа толстая (в среднем 471,5-652,4 мкм), с толщиной мезофилла 431,5-571,1 мкм в среднем. Палисадная ткань 186,2-272,1 мкм толщиной. Губчатый мезофилл плотный, в среднем 214,8-291,0 мкм толщиной, межклетники слабо развиты. Пучки закрытые коллатеральные.

\section{Обсуждение}

E. purpurea произрастает в природе в восточных и юго-восточных районах Северной Америки в разреженных лесах, прериях, на полянах, по берегам рек, водоемов, в зарослях кустарников. Диплоид $(2 \mathrm{n}=22)$ (Urbatsch et al., 2006).

Видам рода эхинацея необходимы хорошо освещенные участки, однако эхинацея пурпурная толерантна к затенению и является засухоустойчивым видом (Foster, 1991), но требует более высокого содержания влаги в почве по сравнению с эхинацеей бледной.

На основе физиологических исследований, проведенных Chapman \& Auge (1994), установлено, что E. purpurea отличается высокой устойчивостью к обезвоживанию. Данное свойство позволяет ей произрастать на сухих местообитаниях, в условиях с высокой инсоляцией и со значительными перерывами в выпадении осадков. В то же время, наличие развитой системы придаточных корней указывает на возможность хорошо использовать поверхностную влагу и питательные вещества, то есть произрастать в условиях с влажными почвами (Cech, 2002). Наличие довольно крупных листьев также можно рассматривать как специализацию к условиям умеренного увлажнения и возможность адаптироваться к менее освещенным местообитаниям. Подобная комбинация приспособительных признаков позволяет эхинацее пурпурной выживать в довольно разнообразных микроклиматических условиях.

Samorodov \& Pospelov (2001) указывают на высокую экологическую пластичность эхинацеи пурпурной с относительно большим запасом генетической изменчивости, обеспечивающим ей успешную адаптацию к новым местообитаниям при интродукции. Anishchenko \& Shishlova (2009), Protopopova \& Shevera (2014) относят данный вид к ксеромезофитам. Anishchenko \& Shishlova (2009) установили положительную корреляцию между количеством осадков, выпавших за вегетационный сезон и вегетативным ростом, развитием и накоплением фитомассы эхинацеи. Причем если у однолетних растений при недостатке влаги наблюдалось лишь замедление роста и развития, то для двулетних и многолетних экземпляров засуха становилась причиной усыхания листьев.

Полученные общие характеристики анатомии листа $E$. purpurea соответствуют приводимым в литературе (Samorodov \& Pospelov, 2001; Kurkin et al., 2009; Upton et al., 2011). По числу устьиц на верхней эпидерме изученный образец близок к растениям, выращиваемым в Украине. Число устьиц на нижней эпидерме листовой пластинки эхинацеи пурпурной оказалось в 2,4 раза меньше показателей, приводимых Samorodov \& Pospelov (2001) для растений, выращиваемых в Украине, и в 2,4-2,6 раза больше значений, полученных S. Atkočiūnaitė (2007) в Литве.

Оценка плотности расположения устьиц обычно используется для характеристики способности листа регулировать водообмен. По-видимому, данный показатель в значительной степени зависит от условий выращивания, характеризуется широкой амплитудой изменчивости и может рассматриваться как показатель, отражающий адаптационный потенциал вида.

При сравнении полученных показателей оказалось, что стеблевые листья достоверно (при уровне значимости $\mathrm{P}<0,05$ ) превосходили розеточные по толщине мезофилла, палисадной и губчатой ткани, толщине верхней эпидермы, размерам клеток верхнего слоя мезофилла, плотности опушения нижней эпидермы и характеризовались более сильным развитием ксилемы по отношению к флоэме, проявляя комплекс ксероморфных признаков. Согласно закону, установленному В. Р. Заленским (Stepanov \& Shliakhtin, 2015), существует ярусная изменчивость анатомического строения листа, которая проявляется в том, что чем выше расположен лист на стебле, тем сильнее у него выражены признаки ксеромофности, повышающие засухоустойчивость, что согласуется с результатами проведенного исследования. Стеблевые листья не имели достоверно значимых отличий по плотности опушения верхней и нижней стороны листовых пластинок.

Оценка изменчивости изученных признаков строения листовой пластинки эхинацеи пурпурной показала, что большая часть параметров, имеющих достоверно значимые отличия при уровне значимости $\mathrm{P}<0,05$, относятся к маловариабельным $(\mathrm{CV}<20 \%)$ и являются стабильными. Из количественных признаков низкой изменчивостью (CV до 11,2\%) характеризовались число клеток верхней и нижней эпидермы, площадь поперечного сечения ксилемы и флоэмы, проводящего пучка. Из морфометрических - толщина пластинки листа, размеры устьиц, а также отношение площадей поперечного сечения ксилемы и флоэме. У розеточных листьев низкая изменчивость (CV меньше 10\%) отмечена для толщины мезофилла, палисадной и губчатой паренхимы, а также высоты клеток верхнего слоя мезофилла, а у стеблевых листьев - для толщины верхней эпидермы.

Такие признаки анатомии стеблевых листьев как размеры клеток верхнего слоя мезофилла, толщина палисадной ткани, отношение палисадной к губчатой ткани, у стеблевых листьев отнесены к средневариабельным (CV = 20,0-27,4\%).

Очень высокий уровень изменчивости $(\mathrm{CV}=233,9-366,4 \%)$ отмечен для количественных признаков, характеризующих плотность опушения листьев, а для стеблевых листьев: число устьиц $(\mathrm{CV}=192,5 \%)$ и соответственно устьичный индекс верхней эпидермы $(\mathrm{CV}=186,2 \%)$.

Число клеток и устьиц нижней эпидермы розеточного и стеблевого листа эхинацеи пурпурной относится к одной генеральной совокупности и не имеет статистически значимых отличий средних и дисперсий (t-критерий $=0,2$ и -1,2, $\mathrm{P}=0,8$ и 0,2; F-ratio var. = 1,1 и $1,5, \mathrm{P}$ var. $=0,8$ и 0,4 соответственно). В листовой пластинке эхинацеи пурпурной выявлены признаки как мезоморфной (наличие относительно крупных дорзовентральных листьев, дифференцированных на палисадную и губчатую паренхиму; умеренное развитие покровной, проводящей и механической тканей; развитая ксилема), так и ксероморфно-гелиоморфной структуры (наличие кутикулы, трихом и хорошо развитой столбчатой паренхимы; хорошо развитая ксилема; листья более-менее толстые с густой сетью жилок и большим числом устьиц на нижней эпидерме (187-198)). 
Проведенные исследования позволяют считать эхинацею пурпурную ксеромезофитом, способным выносить временный дефицит влаги, что благоприятно для культивирования вида в условиях подтайги Западной Сибири с умеренным увлажнением. В условиях, когда корневая система вида расположена относительно поверхностно, адаптация к условиям ограничения атмосферной и почвенной влаги идет по пути развития приспособлений, уменьшающих испарение.

Важная роль в процессе адаптогенеза эхинацеи пурпурной, по-видимому, принадлежит эндогенной изменчивости морфологических и анатомических признаков.

E. pallida произрастает в каменистых прериях, на высокотравных лугах, открытых залесенных склонах, полянах на высоте 5001500 м над у. м. в Северной Америке в Восточном Канзасе, Оклахоме, Западном Арканзасе, Миссури и др. Аллотетраплоид, возможно возникший в результате гибридизации E. sanguinea и $E$. simulata (Urbatsch et al., 2006; Keller, 2012).

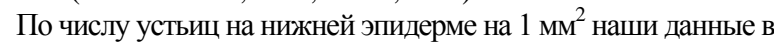
1,4-2,0 раза уступают значениям, приводимым Samorodov \& Pospelov (2001) в Украине, однако значительно (в 4,6-6,5 раза) превосходят результаты, полученные в Литве Kmitienė \& Ragažinskiené (2008). Значения устьичного индекса верхней эпидермы близки к полученным Kmitienė \& Ragažinskienė (2008) - 21,9, однако значения устьичного индекса нижней эпидермы оказались в 2,1-2,2 раза выше, чем в Литве. Возможно, показатели, характеризующие количество устьиц на единицу площади листовой пластинки, наряду с плотностью опушения, отличаются значительной изменчивостью и являются адаптивно значимыми.

Большая часть исследованных параметров относится к маловариабельным $(\mathrm{CV}<20 \%)$. Наиболее низкой изменчивостью $(\mathrm{CV} \leq$ $10 \%)$ характеризовались размеры устьиц, толщина пластинки и мезофилла листа, толщина палисадной ткани, площадь ксилемы, площадь пучка, у розеточных листьев также толщина губчатой ткани, отношение палисадной и губчатой паренхимы, ширина клеток верхнего слоя мезофилла. Некоторые количественные признаки (число устьиц, устьичный индекс стеблевых листьев) являются средневариабельными (CV 20-24\%). Очень высокой изменчивостью с амплитудой 233,8-346,1\%, как и у E. purpurea, отличалась плотность опушения листовой пластинки. Количественные и морфометрические признаки строения розеточного и стеблевого листа у эхинацеи бледной близки. Однако стеблевые листья отличаются более толстой пластинкой с более мощной паренхимой и площадью пучков, что связано, вероятно, с их определенным структурным градиентом в пределах растения (закон Заленского). Если розеточный лист E. purpurea достоверно отличается большей площадью проводящей системы восходящего тока, у E. pallida, напротив, большую площадь имеет ксилема стеблевого листа. Вместе с тем, следует отметить, что такие показатели как отношение толщины палисадной к толщине губчатой паренхимы и отношение площадей поперечного сечения ксилемы и флоэмы у стеблевых и розеточных листьев у эхинацеи бледной практически одинаковы.

При оценке достоверности различий полученных анатомических данных между двумя исследованными видами получены следующие результаты. Большая часть параметров, имеющих достоверно значимые отличия при уровне значимости $\mathrm{P}<0,05$, относятся к маловариабельным (CV $<20 \%)$ и являются стабильными. Отмечено 17-18 характеристик, имеющих достоверные отличия средних значений при $\mathrm{P}<0,05$, с учетом отличий дисперсий - 10 .

Таким образом, с учетом отличий дисперсий, выявлено 10 характеристик, имеющих достоверные отличия средних значений при сравнении листьев E. purpurea и E. pallida: размеры устьиц нижней эпидермы, толщина мезофилла листа, его слоев и пластинки листа, свободной от проводящих пучков, площадь поперечного сечения проводящих пучков и их составляющих (табл.).

При сравнении E. purpurea и E. pallida, выявлены признаки ксероморфности и гелиофитности листа эхинацеи бледной, повышающие ее засухоустойчивость: более узкие и толстые листья, «изолатеральная» тенденция (мезофилл характеризуется плотной упаковкой, сильным развитием палисадной паренхимы, малым объемом межклетников); наличие трихом, которые имеют более сложное строение. E. pallida также отличается более значительным развитием элементов восходящего тока по отношению к флоэме (площадь поперечного сечения ксилемы в 1,6 раза превосходит площадь поперечного сечения флоэмы) и значительным числом устьиц на верхней эпидерме. Более высокая степень проявления ксеромофных признаков у эхинацеи бледной по сравнению с эхинацеей пурпурной является, по-видимому, наследственно закрепленной, то есть E. pallida является ксерофитом, приспособленным к атмосферной и почвенной засухе.

Признаки, по которым обнаружены различия между изученными образцами, относят в экологической анатомии к числу адаптивно значимых.

\section{Выводы}

Исследование эпидермальных структур двух видов эхинацеи показало, что для них характерен аномоцитный тип устьичного аппарата. Тип листа амфистоматический, розеточные листья эхинацеи пурпурной гипостоматические. Выявлены признаки мезоморфной и ксероморфно-гелиоморфной структуры листовой пластинки Е. purpurea и комплекс ксероморфно-гелиофитных признаков листа E. pallida.

Уровень и амплитуда изменчивости количественных и морфометрических признаков, их парные корреляции показали, что такие признаки могут рассматриваться как показатели, отражающие адаптационный потенциал видов.

Работа выполнена при поддержке Министерства образования и науки Российской Федерации (проект № 37.7810.2017/8.9).

\section{References}

Anishchenko, L. V., \& Shishlova, Z. N. (2009). Introdukciya ehkhinacei purpurnoj (Echinacea purpurea (L.) Moench) v botanicheskom sadu YuFU [The introduction of Echinacea purpurea (L.) Moench in the Botanical Garden SFedU]. Proceedings of Voronezh State University. Series: Chemistry, Biology, Pharmacy, 2, 89-94 (in Russian).

Atkočiūnaitè, S. (2007). Ežiuolès (Echinacea Moench.) genties rūšių anatominès ir morfologinès sandaros savitumai [Characteristics of the anatomical and morphological structure of Echinacea Moench.]. Vilnius (in Lithuanian).

Barnes, J., Anderson, L. A., Gibbons, S., \& Phillipson, J. D. (2005). Echinacea species (Echinacea angustifolia (DC.) Hell., Echinacea pallida (Nutt.) Nutt., Echinacea purpurea (L.) Moench.): A review of their chemistry, pharmacology and clinical properties. Journal of Pharmacy and Pharmacology, 57, 929-954.

Bauer, R. (1999). Chemistry, analysis and immunological investigations of Echinacea phytopharmaceuticals. In: Wagner, H. (Ed.). Immunomodulatory agents from plants, Basel. Birkhäuser Verlag, Berlin, 41-88.

Belaeva, T. N., Butenkova, A. N., \& Astafurova, T. P. (2014). Phlox sibirica L. in South Siberia. Biosciences Biotechnology Research Asia, 11(1), 371-376.

Birt, D. F., Widrlechner, M. P., Lalone, C. A., Wu, L., Bae, J., Solco, A. K., Kraus, G. A., Murphy, P. A., Wurtele, E. S., Leng, Q., Hebert, S. C., Maury, W. J, \& Price, J. P. (2008). Echinacea in infection. American Journal of Clinical Nutrition, 87(2), 488S-492S.

Cech, R. (2002). Growing at-risk medicinal herbs-cultivation, conservation and ecology. Horizon Herbs, Williams, OR.

Chapman, D. S., \& Auge, R. M. (1994). Physiological mechanisms of drought resistance in four native ornamental perennials. Journal of the American Society for Horticultural Science, 119(2), 299-306.

Dom, M., Knick, E., \& Lewith, G. (1997). Placebo-controlled, double-blind study of Echinacea pallida radix in upper respiratory tract infections. Complementary Therapies Medicine, 5, 40-42.

Dyakonova, Y. V., Oproshans'ka, T. V., Kislichenko, V. S., \& Hvorost, O. P. (2011). Viznachennya morfologo-anatomichnih oznak travi ekhinaceji blidoji [Determination of morphological and anatomical signs of the herb of Echinacea pallida]. Ukrajins'kyj Medichnyj Al'manah, 14(2), 55-56 (in Ukrainian).

El-Gengaihi, S. E., Shalaby, A. S., Agina, E. A., \& Hendawy, S. F. (2008). Alkylamides of Echinacea purpurea L. as influenced by plant ontogony and fertilization. Journal of Herbs, Spices and Medicinal Plants, 5(4), 35-41.

Foster, S. (1991). Echinacea: Nature's immune enhancer. Healing Arts Press, Rochester, VT. 
Getko, N. V., Kabusheva, I. I., \& Kronivec, V. S. (2000). Issledovanie korrelyacionnyh svyazej mezhdu morfologicheskimi priznakami rastenij Echinacea purpurea (L.) Moench, anatomiej list'ev i soderzhaniem v nih oksikorichnyh kislot [Investigation of the correlation between the morphological features of Echinacea purpurea (L.) Moench., the anatomy of the leaves and the content of oxycinnamic acids in them]. In: Vivchennya ontogenezu roslin prirodnoji ta kul'turnoji flor u botanichnyh zakladah i dendroparkah Evrazii. Poltava. Pp. 71-73 (in Russian).

Hu, C., \& Kitts, D. D. (2000). Studies on the antioxidant activity of Echinacea root extract. Journal of Agricultural and Food Chemistry, 48(5), 1466-1472.

Kashinskij, S. D. (Ed.). (1982). Klimat Tomska [The climate of Tomsk]. Gidrometeoizdat, Leningrad (in Russian).

Kästner, A. (1972). Blattepidermis-Strukturen bei Carlina [Structure of Carlina leaves]. Flora, 161(3), 225-255 (in German).

Keller, A. C. (2012). Swiss Echinacea extract shown safe and effective in preventing colds in largest Echinacea clinical trial. HerbalGram, 96, 28-29.

Keller, H. W. (1962). An anatomical study of the genus Echinacea. The University of Kansas, 3, 1-97.

Kindscher, K. (Ed.). (2016). Echinacea: Herbal medicine with a wild history. Springer International Publishing, Switzerland.

Kmitienė, G., \& Ragažinskienė, O. (2008). Blyškiosios ežiuolès (Echinacea pallida) vegetatyvinių organų anatominès sandaros savitumai [Peculiarities of anatomical structure of vegetative organs of Echinacea pallida]. Botanica Lithuanica, 14(2), 83-87.

Kurkin, V. A., Chepurnova, A. S., Ryzhov, V. M., Tarasenko, L. V., Suvorova, G. N., \& Avdeeva, E. V. (2009). Anatomicheskoe i morfologicheskoe izuchenie travy ehkhinacei purpurnoj s pomoshch'yu cifrovoj mikroskopii [Anatomic and morphological study of the herbs of Echinacea purpurea by help of digital microscopy]. Medical Almanac, 2(7), 204-206 (in Russian).

Leung, A. Y., \& Foster, S. (1996). Encyclopedia of common natural ingreadients used in food, drugs and cosmetics. John Wiley \& Sons Inc., New York, Chichester, Brisbane, Toronto, Singapore.

Nekhajchenko, D. V., Koksheeva, I. M., \& Kislov, D. E. (2014). Izmenchivost' ehpidermal'nyh struktur lista Hydrangea paniculata (Hydrangeacea) v uslo- viyah kul'tury [Variability of the epidermal structures of Hydrangea paniculata (Hydrangeaceae) leaf under culture conditions]. The Bulletin of KrasGAU, 12, 52-57 (in Russian).

Perry, N. B., Burgess, E. J., \& Glennie, V. A. (2001). Echinacea standardization: Analytical methods for phenolic compounds and typical levels in medicinal species. Journal of Agricultural and Food Chemistry, 49(4), 1702-1706.

Pietta, P., Simonetti, P., Gardana, C., Brusamolino, A., Morazzoni, P., \& Bombardelli, E. (1998). Catechin metabolites after intake of green tea infusions. Biofactors, 8, 111-118.

Protopopova, V. V., \& Shevera, M. V. (2014). Engasiophytes of the Ukrainian flora. Biodiversity: Research and Conservation, 35, 31-46.

Samorodov, V. N., \& Pospelov, S. V. (2001). Vidy roda Ehkhinaceya (Echinacea Moench) v agrofitocenozah lesostepi Ukrainy: Desyatiletnie itogi introdukcii, izucheniya biologii i vozdelyvaniya [Species of the genus Echinacea Moench in the agrophytocenoses of the Forest-Steppe of Ukraine: Ten-year results of introduction, study of biology and cultivation]. Bulletin of Poltava State Agrarian Academy, 4, 48-58 (in Russian).

Sloley, B. D., Urichuk, L. J., Tywin, C., Coutts, R. T., Pang, P. K. T., \& Shan, J. J. (2001). Comparison of chemical components and antioxidant capacity of different Echinacea species. Journal of Pharmacy and Pharmacology, 53, 849-857.

Speroni, E., Govoni, P., Guizzardi, S., Renzullia, C., \& Guerra, M. C. (2002). Anti-inflammatory and cicatrizing activity of Echinacea pallida Nutt. root extract. Journal of Ethnopharmacology, 79(2), 265-272.

Stepanov, S. A., \& Shliakhtin, G. V. (2015). Saratovskiye istoki i puti izucheniya fiziologii rasteniy $\mathrm{v}$ Rossii [The Saratov sources and ways of studying physiology of plants in Russia]. Izvestiya of Saratov University. New Series. Series: Chemistry. Biology. Ecology, 15(4), 42-49 (in Russian).

Upton, R., Graff, A., Jolliffe, G., Länger, R., \& Williamson, E. (Eds.). (2011). American herbal pharmacopoeia: Botanical pharmacognosy - microscopic characterization of botanical medicines. CRC Press, Boca Raton, FL.

Urbatsch, L. E., Neubig, K. M., \& Cox, P. B. (2006). Echinacea Moench. In: Flora of North America, Magnoliophyta: Asteridae: Asteraceae, 21, 88-92. 